\section{O aleitamento materno na perspectiva da vulnerabilidade programática e do cuidado}

\author{
Breastfeeding from the perspective of \\ programmatic vulnerability and care
La lactancia materna desde la perspectiva de la vulnerabilidad programática y de cuidado

\begin{abstract}
Based on experiences and reflections reported by health professionals, the aim of this study was to critically analyze the actions, situations, and decisions in healthcare services that involve breastfeeding, examining aspects that favor or limit its possibilities. This was a qualitative study based on the conceptual framework of vulnerability and healthcare, using focus groups with 25 healthcare professionals participating in the Committee on Breastfeeding in Londrina, Paraná State, Brazil. The material was produced with a comprehensive format, focusing on questions that involved the breastfeeding process and its approaches and decisions. The study raises issues for understanding how the way mothers and families deal with breastfeeding is linked to organization of the practices and individual and social aspects, requiring integration between practical and technical/scientific knowledge. The article portrays the complexity of healthcare for women and children, allowing an enhanced approach to routine healthcare and the related strategies for breastfeeding.
\end{abstract}

Breast Feeding; Delivery of Health Care; Health Services; Health Personnel
Sarah Nancy Deggau Hegeto de Souza 1 Débora Falleiros de Mello 2 José Ricardo de Carvalho Mesquita Ayres 3

\section{Resumo}

O objetivo do estudo foi analisar criticamente, com base em experiências e reflexões narradas por profissionais de saúde, ações, situações $e$ decisões que envolvem o aleitamento materno no âmbito dos serviços de saúde, examinando aspectos que favorecem ou restringem possibilidades de amamentação. Estudo qualitativo, baseado no quadro conceitual da vulnerabilidade e do cuidado em saúde, utilizou grupos focais e entrevistas com 25 profissionais participantes do Comitê de Aleitamento Materno, em Londrina, Paraná, Brasil. O material produzido foi elaborado de forma compreensivo-interpretativa, com foco nas questões que envolvem o processo de amamentar, seus caminhos e decisões. O estudo traz elementos para entender que a maneira como as mães e famílias lidam com o aleitamento materno está ligada ao modo como as práticas estão organizadas e com os aspectos individuais e sociais, demandando integração entre saberes práticos e técnico-científicos. Retrata a complexidade do cuidado em saúde da mulher e da criança, possibilitando uma aproximação mais rica ao cotidiano da assistência e das estratégias adotadas.

Aleitamento Materno; Assistência à Saúde; Serviços de Saúde; Pessoal de Saúde 


\section{Introdução}

A proteção, a promoção e o apoio ao aleitamento materno têm sido uma estratégia mundialmente relevante no setor de saúde e outros setores sociais para, entre outros esforços, melhorar as condições de saúde das crianças.

A convicção de que o aleitamento materno é o melhor alimento para a criança é defendida por várias organizações de saúde, em busca da redução da morbimortalidade infantil. Órgãos internacionais da saúde, como a Organização Mundial da Saúde (OMS) e o Fundo das Nações Unidas para a Infância (UNICEF), estabeleceram a nutrição infantil como uma de suas prioridades. As práticas alimentares têm impacto significativo no estado nutricional, crescimento e desenvolvimento, saúde e sobrevivência das crianças 1 .

Os benefícios do aleitamento materno para as crianças têm sido relacionados às menores taxas de diarreia, infecções do trato respiratório, otite média e outras infecções e menor mortalidade por essas doenças em crianças amamentadas quando comparadas às não amamentadas 2 .

A literatura especializada aponta, como vantagens do aleitamento materno para a saúde da mulher, a redução de estresse e mau humor, mediada pela ocitocina, a sensação de bem-estar, devido à liberação endógena de betaendorfina, a promoção da contração uterina pela ocitocina liberada com a sucção do bebê, entre outras, além de indicar que, a longo prazo, a amamentação materna reduz o risco de diversos tipos de doenças, como câncer, artrite reumatoide e osteoporose 3 .

Evidências de vários países indicam que melhorias nos indicadores de aleitamento materno são possíveis na presença do direcionamento efetivo de ações e, entre as medidas, enfatizam o início precoce da amamentação nas maternidades e a capacitação dos profissionais de saúde para o aconselhamento de mulheres acerca do aleitamento materno 4 .

A provisão de adequado suporte tem sido um fator importante para a questão da duração do aleitamento materno ${ }^{5}$. $\mathrm{O}$ apoio pós-parto às mulheres pode trazer efeitos positivos, em especial para jovens e primíparas, com repercussões na amamentação por mais tempo, maior autoestima, menos depressão e mães mais aptas a cuidar dos bebês 6 . Os profissionais de saúde são mais efetivos no suporte ao aleitamento materno se suas atitudes são positivas, com habilidades e conhecimentos apropriados para auxiliar a mulher na amamentação 7 .

Essa agenda global é recomendada, mas os indicadores de início e de duração do alei- tamento materno têm sido baixos em muitos países 5,8 .

O modo como a questão é tratada na literatura sobre o assunto tende, contudo, a reduzir a questão de amamentar ou não a uma espécie de decisão individual, à vontade da mulher (ou à falta dela). Mas até que ponto a "escolha" da mulher, não obstante ser aspecto relevante, constitui uma perspectiva suficiente para abordar a questão desde o ponto de vista das preocupações da Saúde Pública? A posição adotada no presente trabalho é que essa é uma perspectiva limitada e limitante para a construção de efetivas respostas ao desafio da amamentação como prática de promoção e proteção da saúde. A hipótese desenvolvida no presente estudo é de que, a despeito do desenvolvimento das estratégias governamentais federais, estaduais e locais, os serviços de saúde ainda estão criando, ou deixando de reduzir, situações de vulnerabilidade para o não aleitamento, isto é, aspectos programáticos não estão propiciando a prática da amamentação em escala coletiva, apesar de seus conhecidos benefícios. Defende-se que há lacunas assistenciais que precisam ser identificadas e problematizadas para que as mulheres e suas famílias tenham acesso aos recursos apropriados para poderem decidir de modo ativo e autônomo sobre a amamentação e sustentar sua decisão.

O presente estudo tem como objetivo analisar criticamente, com base em experiências e reflexões narradas por profissionais de saúde, ações, situações e decisões que envolvem o aleitamento materno no âmbito dos serviços de saúde, examinando aspectos que favorecem ou restringem possibilidades de amamentação.

\section{Método}

Trata-se de estudo qualitativo ${ }^{9}$, baseado em entrevistas, em profundidade, com profissionais de saúde participantes do Comitê de Aleitamento Materno do Município de Londrina, Paraná, Brasil. A construção do roteiro de entrevista e a interpretação das narrativas construídas a partir dele estão fundamentadas no quadro conceitual da vulnerabilidade 10 e do cuidado em saúde 11 .

A construção do quadro conceitual da vulnerabilidade no campo da saúde é relativamente recente e está relacionada ao entendimento das práticas preventivas e às possibilidades de avançar para além das práticas apoiadas estritamente nos saberes biomédicos e na utilização acrítica dos estudos epidemiológicos de risco.

As pessoas enfrentam diferentes situações de vulnerabilidade, individualmente ou coletivamente, e as situações de agravo ou ameaça à 
saúde podem ser particularizadas pelo reconhecimento de três dimensões interligadas: a individual, a social e a programática ou institucional ${ }^{10}$. As situações individuais, sociais e programáticas não podem ser analisadas de forma isolada, elas são mutuamente referidas e devem ser sempre singularizadas com base nas seguintes questões de ordem prática: vulnerabilidade de quem, vulnerabilidade a quê, vulnerabilidade em que circunstâncias ou condições? As pessoas não são em si vulneráveis, mas podem estar vulneráveis a alguns agravos e não a outros, sob determinadas condições, em diferentes momentos de sua vida 12. Neste estudo, a perspectiva da vulnerabilidade programática é privilegiada, sem tomá-la de forma isolada em relação às dimensões individuais e sociais, compreendendo que as questões do aleitamento materno envolvem aspectos sociais, estruturais, culturais e individuais.

O diferencial que um estudo sobre a decisão de amamentar com base no quadro conceitual da vulnerabilidade procura trazer é, em primeiro lugar, evitar uma leitura individualista e naturalizada da amamentação, o mais habitual na literatura, pensando-a como um processo coletivamente e socialmente produzido. Em segundo lugar, ao privilegiar a dimensão programática como entrada singular na compreensão da vulnerabilidade à não amamentação, a abordagem da questão já fica imediatamente focada no encontro entre mulheres e serviços de saúde, o que potencializa o caráter pragmático dos achados e concorre para superar leituras tecnicistas ou moralistas do modo de operar das ações de saúde em relação à questão. Nesse sentido, a abordagem aqui proposta aproxima-se de correntes que, seja a partir das contribuições dos estudos antropológicos 13,14 , seja na perspectiva da chamada Bioética Crítica 15 , recusam a naturalização dos eventos ligados à maternidade, assim como buscam desconstruir discursos de autoridade que transformam direitos em obrigações e diferenças em desigualdades opressoras.

Remetida ao polo da intervenção, a mesma preocupação de se superar uma visão tecnicista, de estrita aplicação instrumental de saberes biomédicos às situações particulares de atenção à saúde, apoia-se no quadro conceitual do cuidado 11. Entende-se aqui o cuidado como a busca de uma atenção à saúde de base dialógica, isto é, apoiada nos saberes e valores dos diferentes sujeitos envolvidos e sensível aos significados práticos de suas finalidades e métodos - os sentidos éticos, morais, políticos e afetivos das demandas e intervenções no campo da saúde.

Participaram do estudo profissionais de saúde do Comitê de Aleitamento Materno, por meio de grupos focais e entrevistas individuais, com roteiro semiestruturado, contando com a participação de trabalhadores das seguintes áreas: enfermagem, medicina, nutrição, odontologia, técnico em saúde bucal e pedagogia, que atuam na atenção básica ou hospitalar e na gestão dos serviços de saúde do município. O Comitê de Aleitamento Materno foi instituído em Londrina pelo Decreto $n^{\circ} 245$, de 19 de abril de 1995, e congrega diversas instituições, tanto públicas quanto privadas, de saúde e da comunidade, sob a coordenação da Secretaria Municipal de Saúde de Londrina. Esse comitê foi instituído para planejar e coordenar as ações de aleitamento materno do município, e os integrantes representam suas instituições voluntariamente.

A partir da listagem dos membros do Comitê de Aleitamento Materno, as pessoas foram contatadas, buscando a representatividade das categorias profissionais e das instituições participantes. Dessa forma, 25 profissionais, oriundos de catorze serviços de saúde, atenderam voluntariamente ao convite.

Foram realizados dois grupos focais, sendo um de profissionais de saúde que atuam diretamente na assistência à mãe e ao bebê e outro de gestores, responsáveis pelo planejamento e controle das ações. O primeiro grupo teve a participação de dez profissionais, de diferentes categorias, tanto de serviço público como privado, hospitalar e atenção básica. O segundo grupo foi constituído de seis profissionais que atuam na gestão e gerência de serviços de saúde. Os grupos foram realizados em dois dias, um para cada grupo, com duração média de uma hora e quarenta e cinco minutos. O local da realização dos grupos não ocorreu em nenhuma das instituições representadas para que os participantes não se sentissem constrangidos para se expressar

Após a realização dos grupos focais, foram realizadas dez entrevistas individuais com profissionais do Comitê de Aleitamento Materno que haviam sido selecionados para participar dos grupos, mas que, por motivo de indisponibilidade nas datas previstas, não puderam comparecer. A opção pelas entrevistas teve por objetivo aprofundar temas importantes levantados nas discussões dos grupos focais. Esses profissionais também atuavam em unidades básicas de saúde, hospitais públicos e privados, consultório particular, ambulatório de especialidades e pronto atendimento infantil.

O número de entrevistados foi definido ao longo do processo de pesquisa, segundo critério de suficiência, ou seja, quando o material empírico mostrou um conjunto de elementos que permitiu uma compreensão considerada relevante 
para fazer progredir a reflexão e a ação sobre a questão investigada.

Como ponto de partida para as reflexões nos grupos focais e nas entrevistas, foi apresentado aos profissionais de saúde o conjunto de dados sobre prevalência e fatores associados ao aleitamento materno do Município de Londrina, com base nos dados locais de 770 entrevistas com acompanhantes de crianças menores de um ano que compareceram na campanha de vacinação contra poliomielite de agosto de 200816.

O temário elaborado, tanto para a condução dos grupos quanto das entrevistas, seguiu o seguinte roteiro: o que esses números mostram para vocês, no contexto das ações? Como os dados se correlacionam com ações? O que a realidade que vocês descrevem tem a ver com os índices? Onde se encontram as barreiras para a melhoria dos índices? Para você, o que é cuidar/apoiar a mãe que amamenta? Quem são as mães que aderem e quem são as mães que não aderem ao aleitamento materno? O que, nos serviços, tem aproximado ou afastado a mãe da amamentação?

$\mathrm{Na}$ apresentação dos resultados, os participantes são denominados por letras e números quando participaram de entrevistas (E1, E2, E3...) e de grupo focal (GF1, GF2, GF3...).

Na construção e discussão do material empírico dos grupos focais e entrevistas, buscou-se identificar e discutir sentidos e significados organizadores dos relatos acerca de situações, ações, crenças e valores relativos ao aleitamento materno, tomando-se, por referência, um percurso interpretativo com base no quadro conceitual da vulnerabilidade programática e do cuidado em saúde 10,11,17. Todo o material foi digitado e organizado em arquivos individuais. Na interpretação dos depoimentos, foram percorridas as etapas da análise de conteúdo da modalidade temática 9: (a) leitura preliminar do material buscando mapear os sentidos atribuídos pelos sujeitos às perguntas feitas; (b) interpretação dos conteúdos e posicionamentos dos depoentes, expressos e latentes, frente aos sentidos orientadores de seus relatos; (c) elaboração de síntese interpretativa, relendo os conteúdos à luz da hipótese, e de quadro conceitual de orientadores do estudo.

O presente estudo foi aprovado pelo Comitê de Ética em Pesquisa da Universidade Estadual de Londrina, parecer no 079/09, com utilização de termo de consentimento livre e esclarecido.

\section{Resultados e discussão}

A apresentação dos resultados do estudo está aqui organizada com base nas questões que en- volvem o processo de amamentar ou não amamentar, seus caminhos e decisões.

Os profissionais traçam algumas características das mães que decidem amamentar e das que decidem não amamentar:

"Eu vejo que aquelas que tiveram um preparo maior, tiveram alguém, elas já têm uma ideia melhor, já entendem um pouco mais, que elas querem, já entenderam que amamentar é o melhor. Aquelas que não tiveram nada e que têm alguém ao lado, a sogra ou a avó, e que não amamentou, aí piora mais ainda" (GF1).

"Eu vejo que aquelas que já querem amamentar mesmo, que já têm posto na cabeça, elas têm mais vontade. Elas vão por vontade, elas escutam mais o que nós falamos. Aquela que tem um pouco de dúvida, que já teve uma experiência ruim, que não tem o apoio da família, às vezes, elas não aceitam tanto a informação, eu acho que é por conta de não ter um vínculo grande com a gente" (GF9).

"Geralmente, as mães que querem amamentar são as que já amamentaram, é a mãe que tem um vínculo com a criança, é uma mãe que decidiu amamentar antes de chegar no pediatra. [...] é aquela mãe que principalmente o pai ajuda. Se o pai apoiar, acho que é 50\%. As avós também têm bastante influência, e o serviço de saúde sim, é importante" (E9).

Os profissionais percebem diferentes situações entre as mães quanto à disponibilidade e à decisão para amamentar ou não, atribuindo, ao desejo da mulher, apoio familiar, orientações e experiências anteriores. Identificam que a decisão pode já ter sido tomada antes da interação com o profissional.

A partir dos relatos dos profissionais de saúde, há indicativos de aspectos de caráter individual e social, no âmbito familiar, que reduzem a segurança da mãe para iniciar ou continuar o seu processo de amamentação. De forma não descolada desse processo, há interfaces com a vulnerabilidade programática, pois a capacidade de respostas dos serviços de saúde na questão do aleitamento materno não está plenamente voltada para um cuidado integral à saúde. Identificam obstáculos que influenciam as práticas sociais e de saúde, particularmente para efetivar o aleitamento materno.

Há também relatos de preocupações dos profissionais com o pouco conhecimento da mãe sobre como lidar com o bebê:

“... as mães de primeiro filho, quando não são orientadas, são mães que têm muito risco de não amamentar, porque ela não conhece o que vem aí. Por exemplo, vem o bebê chorão, ela vê que o bebê não engorda, vem um pai que não tolera choro, é aquele pai que cobra muito da mãe" (E9). 
"O cansaço, [...] talvez, assim, não capacidade, [...] parece que tudo é difícil. Então, por exemplo, elas falam assim: 'pelo amor de Deus, ele acorda 10 vezes à noite [...], eu preciso de descanso e de dormir'. [...] É aquela mãe que amamenta com todos os músculos contraídos, mesmo não tendo fissura, ela diz: 'Dói, dói, dói'. Mas, não tem fissura, tá tudo bem, não tem problema. 'Mas dói, mas dói.' Puxa vida! Será que isso dói? Para mim, isso é uma outra dor" (E3).

Os profissionais apontam obstáculos que mobilizam as mulheres e suas famílias, que expressam ou não tolerância.

As estratégias de intervenção para redução de vulnerabilidades precisam não abandonar os aspectos individuais, mas considerá-los sempre em suas perspectivas sociais, mesmo em se tratando de atendimentos individuais. A responsabilidade dos serviços e dos profissionais de saúde no que se refere à promoção da saúde e à prevenção de agravos se estende para além da tarefa de alertar as pessoas sobre as possíveis ameaças à sua saúde, mas concorre efetivamente para que "possam responder de forma que superem os obstáculos materiais, culturais e políticos que os mantêm vulneráveis, mesmo quando individualmente alertas" 10 (p. 401).

Outro elemento identificado pelos profissionais foi o tipo de comunicação com as mulheres, que pode influenciar em seu processo de decisão de amamentar:

"Eu acredito que tem que ter o preparo [...], às vezes, só numa palestra que a gente fala, que um encontro é sobre aleitamento materno, aí você joga aquele monte de informações, em um encontro só e não fala mais aquilo. Então, vejo que o preparo é o que vai fazer essa amamentação ser eficaze ter longo prazo, e não é assim, a gente fazer uma palestra só num curso de gestantes sendo que nem todas que vão" (GF9).

"Quando a mãe quer amamentar a gente fica tranquilo e só reforça. Nas que não querem, a gente tenta fazer um trabalho de formiguinha. Eu acho assim, que a gente tem que aprender todo dia a arte de passar a mensagem, que não é fácil. Por quê? Porque cada um de nós tem nossa história de vida, e essa história de vida influencia. [...] Então, será que faltam palestras? Será que falta tanta informação? Ou será que elas ouvem e não absorvem? Por quê? Por causa das condições que elas se encontram? Ou pela história de vida? Então, na minha opinião, na minha experiência, os profissionais têm que descobrir um jeito de chegar até aquela mãe" (E8).

Os profissionais alegam a possibilidade de ainda haver falta de informação e preparo técnico da gestante e puérpera para a amamentação, mas também percebem que a lacuna pode estar além do fornecimento de informação para a mulher. Ela pode estar envolvida muito mais com a forma como isso é realizado, considerando a mãe em sua individualidade e contexto de vida.

Quando se analisa os excertos acima sob a perspectiva do quadro conceitual do cuidado, percebe-se ainda o "predomínio do enfoque instrumental sobre o enfoque prático ou hermenêutico" 11 (p. 157) em nossas práticas de saúde. Isto é, ainda quando se percebe os limites da estratégia da informação e se chega, inclusive, a evocar aspectos da singularidade das biografias, a questão acaba sendo restrita ao grau e à qualidade da exposição à informação ou ao sucesso ou insucesso da "absorção" da informação. Nesse sentido, a mulher é mantida em sua condição de um objeto de intervenção, e essa será considerada fracassada se não produzir o efeito desejado pelo profissional, com base no seu conhecimento técnico. Não seria possível pensar em um cuidado bem-sucedido à mulher que teve uma criança, que a apoie no cuidado dessa criança, que não inclua a amamentação? Ou, indo mais longe, não é possível considerar que a exigência da amamentação possa ser, em certas situações, um obstáculo, mais que um facilitador, na delicada relação entre a mulher e a criança frente ao projeto de felicidade constituinte de suas existências compartilhadas?

Os profissionais mencionam as cobranças em relação ao aleitamento materno:

"Sempre colocam muita cobrança na questão do aleitamento. Nos primeiros dias pós-parto, ninguém pergunta muito e nem dá muita atenção, vai ensinando como é que põe, e põe o bebê, e dizem: 'o bebê tem que mamar, senão você não vai sair [de alta]'. É uma cobrança séria, e não só da equipe, mas de avó. É muito raro alguma mulher colocar, assim, que definiu que não vai querer e alguém apoiou. Se ela decide, ela está sozinha" (E3).

"Primeiramente, é importante escutar aquela mãe, assistir verdadeiramente aquela mãe. [...] Então, às vezes, eu acho que o enfoque tem que começar a mudar. A gente se preocupa tanto com o bebê, e fala e orienta e pergunta o que é que está dando. Mas, em que momento que a gente está dando oportunidade para aquela mãe? Em saber dela, se ela está com dificuldade? Como é que ela está? Se está bom para ela amamentar ou não? Às vezes, nós, enquanto profissionais de saúde, acabamos julgando, querendo ou não, obrigando aquela mãe. Então, acho que falta oportunidade de mudar um pouco de enfoque, de mudar a maneira da gente atender a mãe e o bebê juntos" (E5).

Na visão dos profissionais, a equipe de saúde e a família exercem uma cobrança excessiva e um prejulgamento da mulher. Alguns serviços 
têm agravado as condições de vulnerabilidade ao forçarem a amamentação, tornando uma obrigação a ser cumprida, aumentando a sobrecarga emocional e não respeitando a mulher em suas particularidades.

As rotinas dos serviços de saúde, muitas vezes, levam a situações geradoras de vulnerabilidade, adotando práticas prejudiciais e, de certo modo, não humanizadoras, que, no caso do aleitamento materno e da maternidade, partem de uma visão que remete a um instinto natural e universal, com uma concepção idealizada do ser humano fora da história e da cultura 14 .

Atitudes impositivas dos profissionais podem reforçar a construção cultural de que o ato de amamentar é dever e responsabilidade inerentes à maternidade, fazendo a questão deslizar para um estéril e pernicioso moralismo e culpabilização da mulher que não amamenta. Nesse cenário, a mãe que se sente sobrecarregada com os trabalhos domésticos tenta buscar as soluções dentro dos limites da demanda pessoal, desconsiderando outras possibilidades de lidar com a questão, como a redivisão das tarefas domésticas e maternas, rompendo, por exemplo, com a rigidez da divisão social dos papéis relacionada a gênero ${ }^{18}$. O julgamento da mulher, impelido pela visão do profissional de que o caminho da amamentação é o único possível de ser escolhido e percorrido, a induz a pensar que "o corpo materno se configura como responsável e culpado pelo 'mau jeito', colocando o 'corpo do filho em condição de prejuízos e perigos" 18 ( $\mathrm{p}$. S362). Levar a mãe a essa sensação vai tornar, ainda mais difícil, a possibilidade de ela optar pela amamentação. A mãe não pode ser considerada a única responsável pelo êxito da amamentação ou culpada pelo desmame 19 .

Os estudos epidemiológicos sobre as relações probabilísticas entre aleitamento materno e desfechos para a criança são, como para quaisquer outros eventos em saúde, um útil instrumento para a identificação e dimensionamento de riscos, podendo colaborar para sua prevenção, mas não dão conta do significado prático (ético, moral, político) das situações concretas que estudam ${ }^{10}$. Por isso, sua aplicação dogmática e descontextualizada nas ações de saúde pode levar a um efeito contrário ao desejado, produzindo preconceito, discriminação, estigmatização, dificuldades de relacionamento social, conflitos com os serviços e, dessa forma, mais vulnerabilidades 20. Uma abordagem descontextualizada do risco é a tendência de considerar os indivíduos exclusivamente responsáveis por suas ações, o que leva à culpabilização dos indivíduos. Isso ocorre com a mulher que amamenta, e o fato de não amamentar tende a ser relacionado com uma "displicência" ou irresponsabilidade exclusiva da mulher.

Na perspectiva da vulnerabilidade, não há agente causal em si mesmo. Não há, da mesma forma, condição materna que, por si, possa ser considerada inerente ao risco de desmame, como ser adolescente, ter pouca escolaridade, entre outras. Qualquer condição (física, cognitiva, afetiva, comportamental) somente adquire sentidos concretos no cotidiano vivido e compartilhado, com características que dependem do seu ambiente cultural e sociopolítico, porque é nesses contextos que são construídos, sempre de modo intersubjetivo e relacional, nossas subjetividades, nossos valores e nossas ações 20 .

Face às decisões das mulheres em não amamentar, os profissionais relataram sentimentos de frustração, raiva e desmotivação:

"É muito frustrante você ter uma mãe que não quer amamentar. Eu não sei como as pessoas se sentem, mas eu me sinto frustrada, impotente, com muita raiva da mãe. Tem umas que você via que tinha algum problema que justificava, mas tinha mãe que estava com leite, sabe? Estava com as condições todas favoráveis" (E9).

"É uma frustração grande, porque a equipe sabe da importância do aleitamento e aí se sente impotente, porque o desejo de amamentar e a decisão de amamentar são da mãe. Então, você não pode interferir muito. Você pode orientar, tentar explicar para ela que é o ideal, mas não pode tomar a decisão por ela e forçar. A equipe se sente um pouco incompetente" (E10).

Há certo incômodo dos profissionais com o fato de a mãe expressar verbalmente que não quer amamentar. Eles entendem que é importante insistir, mas há situações em que a insistência não resulta na adesão ao aleitamento materno. O profissional se vê impotente e sentese desmotivado para iniciar um diálogo com o objetivo de compreender as razões e os sentimentos que levaram a mulher àquela decisão e para levantar com ela as alternativas possíveis para a situação que se coloca "supostamente decidida".

Esses sentimentos são o "outro lado" da ênfase quase exclusiva no enfoque instrumental das práticas de saúde, a que nos referíamos acima, e mostram os efeitos "desumanizadores" a que estão submetidos também os profissionais quando a dimensão prática e intersubjetiva do cuidado é completamente colonizada pelo objetivismo tecnicista. A frustração ou a raiva ficam onde poderiam estar o aprendizado e o diálogo, que fariam ambos, profissionais e usuários, mais capazes de achar caminhos realistas, possíveis e desejados, para reduzir as vulnerabilidades de mulheres e crianças. 
A decisão da mãe de não amamentar, em si, não pode ser considerada um fracasso. Ao repensar sobre as motivações que levaram a mulher a decidir pela não amamentação, junto com ela, é possível que perceba que sua decisão interessa àquele profissional e que talvez possa não estar fechada, que o aleitamento materno possa ainda não estar fora de questão. Querer saber os motivos pode levá-la a refletir se aquele era mesmo o único caminho ou se poderia haver outro. Não se deve tomar a decisão já de início como positiva ou negativa, mas como um dado concreto. Há uma necessidade legítima para aquela pessoa se decidir por um caminho e deve-se buscar compreender as necessidades e se essas necessidades se fundem, de alguma forma, com as do profissional de saúde e vice-versa e tentar apresentar alternativas.

Os serviços e profissionais criam ou deixam de reduzir vulnerabilidades para a mulher e para a criança quando se mostram incapazes de perceber diferentes oportunidades de conversa, nas quais possam ser criados diálogos efetivos sobre o assunto. Nesse caso, não se trata de "insistir" no aleitamento materno, mas de se retomar, a cada vez, a troca de ideias sobre o aleitamento materno; não se trata também de colocar o aleitamento materno como um fim em si e, enquanto tal, uma "prova" do compromisso da mãe com a saúde de seu filho, mas de se refletir com a mulher sobre o cuidado de si e de seu filho e de como a amamentação pode (ou não) ser incluída nesse cuidado.

Os profissionais relatam certa desmotivação para estabelecer essa conversa com as mães, impedindo a continuidade da atenção. As escolhas tornam-se processos truncados e com pouco diálogo. No processo da amamentação, "aos profissionais de saúde cabe o acolhimento às mulheres, a compreensão do seu modo de vida e o respeito às suas opiniões, para assim, apoiálas nas decisões" 21 (p. 149). Esse diálogo precisa estar pautado no entendimento das razões e sentimentos das mulheres que as têm levado a tais decisões, sendo importante um bom manejo de cada situação.

Do ponto de vista do quadro da vulnerabilidade programática, é preciso refletir sobre as razões e o modo de lidar com essa desmotivação dos profissionais, compreensível em muitos casos, para o diálogo com as mães sobre as decisões quanto ao aleitamento materno, afinal esse é um aspecto de vulnerabilização ao não aleitamento.

Considerar a decisão da mulher de não amamentar, em si mesma, como um fracasso profissional não faz avançar a atenção à saúde. Isso seria equivalente a assumir que o discurso mé- dico-sanitário é o exclusivo detentor da verdade, e que o não atendimento de suas prescrições configuraria sempre erro ou, no mínimo, ignorância. A adesão ao aleitamento materno e os julgamentos dos profissionais sobre essa adesão, se forem realizados de modo dogmático e autoritário, podem criar um afastamento das mulheres e famílias dos serviços de saúde. Querer o melhor para a saúde da criança é legítimo, mas tomar o aleitamento materno como direito exclusivo da criança pode criar uma situação delicada e danosa, porque faz com que a mulher-mãe passe de detentora de prerrogativas para cumpridora de deveres, dando margem a conflitos emocionais e ao desenvolvimento de ações e de políticas públicas autoritárias na área da saúde e em outros campos, pois as mulheres ficariam vulneráveis à restrição de liberdade, à discriminação, entre outras violações 22 .

Depois que o bebê nasce, não podemos ver a mulher somente como objeto do aleitamento materno do seu filho, mas é importante ampliar nosso olhar e as intervenções quanto às experiências da maternidade e os projetos de vida para aquela mulher. As práticas profissionais, enquanto defensoras do aleitamento materno, precisam ser revisadas e avaliadas constantemente, não tanto em relação às taxas de adesão ao aleitamento, mas o quanto é possível de autonomia em relação ao aleitamento materno, e se as pessoas, de fato, têm condições de tomar suas decisões e têm todo o apoio que elas precisam nas decisões que tomam.

\section{Conclusões}

Espera-se que o presente estudo tenha trazido elementos para entender o lugar ocupado pelas práticas dos serviços e dos profissionais no modo como as mães e famílias lidam com o aleitamento materno, demonstrando a necessidade de integração entre saberes práticos e técnico-científicos no manejo do cuidado da saúde de mulheres e crianças. Os resultados qualitativos retratam a complexidade desse cuidado, possibilitando uma aproximação ao cotidiano da assistência e das estratégias e decisões adotadas.

$\mathrm{O}$ enfoque da vulnerabilidade programática e suas interfaces com as dimensões individuais e sociais trazem contribuições para repensar as práticas de saúde e pode trazer subsídios para a organização do cuidado no que se refere ao manejo do aleitamento materno.

Os profissionais de saúde precisam repensar as atitudes e a forma de interação com as mulheres, lidando com os obstáculos em busca da construção de encontros verdadeiros. Entre os 
efeitos vulnerabilizadores desse "desencontro", podemos identificar: não dar oportunidades para as mães falarem sobre seus medos e dificuldades; não contribuir para a mãe conhecer o seu filho e para compreender seu choro e suas necessidades; não compreender sua falta de paciência e ansiedade; cuidar com foco somente nas informações e no manejo técnico (posição corporal para amamentar, avaliação clínica das mamas, da presença de fissura mamária, posição do bebê para sugar, entre outros); não estar atento às singularidades de cada dupla mãe-bebê; tomar a obrigatoriedade no aleitamento materno como única forma de cuidar.

Os aspectos facilitadores do apoio ao aleitamento materno, à luz do quadro da vulnerabilidade e do cuidado, são: pré-natal com bom vínculo e preparo para a amamentação; conhecer os desejos e interesse da mãe em amamentar e conversar sobre eles; suporte do pai e da família; auxílio durante a amamentação; ouvir a mãe e conversar sobre a maternidade e os cuidados cotidianos com o bebê; compreender seus conflitos e promover um ambiente emocional suficientemente bom para facilitar o relacionamento mãebebê-família, suporte aos profissionais e serviços para lidar com as frustrações e desmotivações decorrentes de desencontros das suas expectativas quanto ao aceitamento materno e às respostas das mães, crianças e famílias.

A prática do aleitamento materno não se beneficia, como vimos, da adoção de um modelo ideal de assistência e de adesão a padrões e normas, mas pode ser um potente fomentador de cuidados se tomada como um horizonte comum para que profissionais de saúde e mulheres possam interagir e trocar experiências e conhecimentos para a promoção e proteção da saúde de mulheres e crianças. Não é simplesmente um modo de fazer com um saber a priori, mas deve ser tomada como uma tecnologia de cuidado em saúde, na qual é importante tematizar valores vitais que não são permanentes, mas envolvem decisões, sempre compartilhadas, sobre quais ações podem e devem ser realizadas a cada momento, em cada situação singular.

\section{Resumen}

El objetivo del estudio, basado en las experiencias de los profesionales de la salud, fue analizar críticamente las acciones, situaciones y decisiones que implican la lactancia materna en los servicios de salud, los aspectos que generan o limitan las posibilidades de lactancia. Se trata de un estudio cualitativo, basado en la teoría conceptual de la vulnerabilidad y el cuidado a la salud. Los datos se obtuvieron por grupos focales y entrevistas, incluyendo a 25 profesionales del comité de lactancia materna en Londrina, Paraná, Brasil. Los datos se analizaron con un enfoque global e interpretativo, centrándose en cuestiones que involucran la práctica de la lactancia materna, sus circunstancias y decisiones. El estudio resalta elementos, con el fin de comprender la manera en la que las madres y familias afrontan la lactancia materna y se relaciona con los aspectos individuales y sociales y la necesidad de integrar la práctica y el conocimiento técnico-científico. Muestra la complejidad de la atención a la salud de las mujeres y los niños, lo que permite un enfoque más cercano en el cuidado diario y las estrategias elegidas.

Lactancia Materna; Prestación de Atención de Salud; Servicios de Salud; Personal de Salud

\section{Colaboradores}

S. N. D. H. Souza e D. F. Mello participaram da concepção do projeto, análise e interpretação dos dados, redação do artigo, revisão crítica do conteúdo intelectual e aprovação final da versão a ser publicada. J. R. C. M. Ayres contribuiu na redação do artigo, revisão crítica do conteúdo intelectual e aprovação final da versão a ser publicada.

\section{Agradecimentos}

Aos profissionais do Comitê de Aleitamento Materno e à Secretaria de Saúde de Londrina, Paraná, Brasil. 


\section{Referências}

1. Organização Mundial da Saúde. Estratégia global para a alimentação de lactentes e crianças de primeira infância. http://www.ibfan.org.br/do cumentos/ibfan/doc-286.pdf (acessado em 20/ Fev/2009).

2. León-Cava N, Luter C, Ross J, Martin L. Quantifying the benefits of breastfeeding: a summary of the evidence. Washington DC: Pan American Health Organization; 2002.

3. Antunes LS, Antunes LAL, Corvino MPF, Maia LC. Amamentação natural como fonte de prevenção em saúde. Ciênc Saúde Coletiva 2008; 13:103-9.

4. United Nations Children's Fund. Tracking progress on child and maternal nutrition: a survival and development priority. New York: United Nations Children's Fund; 2009.

5. Moran VH, Dykes F, Edwards J, Burt S, Whitmore M. An evaluation of the breastfeeding support skills of midwives and voluntary breastfeeding supporters using the breastfeeding support skills tool (BeSST). Matern Child Nutr 2005; 1:241-9.

6. Brüggemann OM, Parpinelli MA, Osis MJD. Evidências sobre o suporte durante o trabalho de parto/parto: uma revisão da literatura. Cad Saúde Pública 2005; 21:1316-27.

7. Clifford J, McIntyre E. Who supports breastfeeding? Breastfeed Rev 2008; 16:9-19.

8. Cwiek D, Branecka-Worznic D, Fryc D, Grochan E, Malinowski W. Reasons for giving up breastfeeding and support during problems with lactation in the north-western part of Poland. Ann Acad Med Stetin 2010; 56:129-32.

9. Minayo MCS. O desafio do conhecimento: pesquisa qualitativa em saúde. 10ā Ed. São Paulo: Editora Hucitec; 2007.

10. Ayres JRCM, Calazans GJ, Saletti Filho HC, França Jr. I. Risco, vulnerabilidade e práticas de prevenção e promoção da saúde. In: Campos GWS, Minayo MCS, Andrade LOM, Akerman M, Drumond Junior Carvalho YM, organizadores. Tratado de saúde coletiva. São Paulo: Editora Hucitec; 2006. p. 375-417.

11. Ayres JRCM. Cuidado: trabalho e interação nas práticas de saúde. Rio de Janeiro: Centro de Estudos e Pesquisa em Saúde Coletiva, Instituto de Medicina Social, Universidade do Estado do Rio de Janeiro/ABRASCO; 2009. (Coleção Clássicos para Integralidade em Saúde).
12. Ayres JRCM, Paiva V, Buchalla CM. Direitos huma nos e vulnerabilidade na prevenção e promoção da saúde: uma introdução. In: Paiva V, Ayres JRCM, Buchalla CM, organizadores. Vulnerabilidade e direitos humanos: prevenção e promoção da saúde. Livro I: da doença à cidadania. Curitiba: Editora Juruá; 2012. p. 9-22.

13. Sandre-Pereira G. Amamentação e sexualidade. Revista Estudos Feministas 2003; 11:467-91.

14. Tornquist CS. Armadilhas da nova era: natureza e maternidade no ideário da humanização do parto. Revista Estudos Feministas 2002; 10:483-92.

15. Diniz D, Guilhem D. Feminismo, bioética e vulnerabilidade. Revista Estudos Feministas 2000; 8:237-44

16. Souza SNDH, Migoto MT, Rossetto EG, Mello DF. Prevalence of breastfeeding and associated factors in the municipality of Londrina (PR, Brazil). Acta Paul Enferm 2012; 25:29-35.

17. Ayres JRCM. Para comprender el sentido práctico de las acciones de salud: contribuciones de la hermenéutica filosófica. Salud Colect 2008; 4 : 159-72.

18. Nakano AMS. As vivências da amamentação para um grupo de mulheres: nos limites de ser "o corpo para o filho" e de ser "o corpo para si". Cad Saúde Pública 2003; 19 Suppl 2:S355-63.

19. Almeida JAG. Prefácio. In: Castro LMCP, Araújo LDS, organizadores. Aleitamento materno: manu al prático. 2a Ed. Londrina: Athalaia; 2006. p. 15-9.

20. Ayres JRCM, Paiva V, Franca Jr. I. From natural history of disease to vulnerability: changing concepts and practices in contemporary public health. In: Parker R, Sommer M, editors. The routledge handbook of global public health. New York: Routledge; 2011. p. 98-107.

21. Monteiro JCS, Gomes FA, Nakano AMS. Amamentação e o seio feminino: uma análise sob a ótica da sexualidade e dos direitos reprodutivos. Texto \& Contexto Enferm 2006; 15:146-50.

22. França Jr. I, Ayres JRCM. Amamentar é um direito humano? São Paulo: Serviço Nacional de Aprendizagem Comercial; 2000.

Recebido em 06/Ago/2012

Versão final reapresentada em 26/Jan/2013

Aprovado em 08/Fev/2013 